\title{
A justiça no tempo, o tempo da justiça
}

Sérgio Adorno e Wânia Pasinato

Este artigo trata da morosidade da justiça. Pouco importando a natureza dos litígios - se cíveis ou criminais - , ou o perfil dos litigantes - se cidadãos comuns, corporações ou autoridades públicas-, écorrentea suspeita deque a intervenção judicial na mediação de conflitos é lenta e prevê incontáveis possibilidades de recursos que retardam decisões, além de se sujeitar ao acúmulo de processos e às singularidades burocráticas de uma sociedade como a brasileira. No domínio da justiça cível, não são poucos os proble mas. As corporações empresariais reclamam que o tempo da intervenção judicial não acompanha o ritmo dos negócios imposto pelo mercado. Problemas decorrentes de morosidade judicial têm sido igualmente apontados em disputas fiscais, indenizações e cobranças de toda sorte. $N$ ão sem razão, vimos assistindo, cada vez mais na sociedade, à disseminação de sentimentos coletivos segundo os quais, se a justiça tarda, as leis não são aplicadas.

No domínio da justiça criminal não tem sido diferente. D esdeao menos três décadas, a sociedade brasileira vem conhecendo o crescimento de todas as modalidades decrimes e deconflitos interpessoaisqueresultam em desfechos fatais. 0 scrimes cresceram e se tornaram mais graves e mais violentos. $M$ anifestações públicas de medo e insegurança ganharam intensidade e dramaticidade, como deixam entrever as narrativas cotidianas que comparecem diariamente às colunas policiais da mídia impressa eàs manchetes da mídia eletrônica e televisiva. No rol das mais inquietantes preocupações na- 
1. Segundo D ahrendorf (1987), a era contemporânea está dominada pelo sentimento generalizado de medo e insegurança coletivos diante da escalada do crimee da violência. 0 dilema da sociedaderepousa no embate entre duasforças antagônicas e opostas: as lutas em torno do contrato e dos direitos são concomitantesaum processo reverso, qual seja, a erosão da lei e da ordem, cujo principal indicador é a atual incapacidade do Estado de cuidar da segurança dos cidadãos. Um dos indicadores desse processo reverso é a disseminação da impunidade, isto é, a desistência sistemática de aplicação de punição para quaisquer crimes, pouco importando sua natureza ou gravidade.

2. Ver Correa (1983).

3. Ver Pinheiro, Adorno, Cardia et al. (1999). A pesquisamobilizou os seguintespesquisadores: Paulo Sérgio Pinheiro, Sérgio Adorno, $N$ ancy Cardia, Malak Poppovic (1993-94), na coordenação; Anamaria C . cionais, a insegurança ea violência ocupam posição de destaque, conforme demonstram sondagens de opinião realizadas por distintos institutos eestudos acadêmicos. M uitos crêem que uma das principais causas, senão a mais importante, desse cenário social éa impunidade penal ${ }^{1}$. Independentemente das razões pelas quais, no fluxo de justiça criminal, crimes deixam de ser punidos, éforte, sobretudo entre especialistas, 0 argumento que reputa aos trâmites processuais, altamente ritualizados e burocratizados, uma das causas da impunidade. A apuração de responsabilidade penal esvai-se no tempo. 0 longo interval o que percorre desdeo registro policial, passando pelos procedimentos investigatórios e pelos detal hados procedimentos judiciários que contemplam o contencioso entre acusação e defesa, até a sentença decisória, parece contribuir para a indeterminação da responsabilidade.

0 tempo émedida da justiça. Se longo, écada vez menos provável corrigir fal has técnicas na condução administrativa dos procedimentos ou localizar testemunhas, eventuais vítimas, possíveis agressores. Securto, corre-se o risco de suprimir direitos consagrados na Constituição enas leis processuais penais, instituindo, em lugar da justiça, a injustiça. Para o cidadão comum, o tempo é lugar da memória coletiva. Se ele consegue estabelecer vínculos entre o crime cometido e a aplicação de sanção penal, experimenta a sensação de que a justiça foi aplicada.

Reconhecendo o tempo como medida de justiça, este artigo explora a questão da morosidade no julgamento de crimes singulares, como são os casos de linchamentos. Procura-se sugerir queo lapso de tempo entre o início dos procedimentos judiciais e a sentença decisória, mais do que simples medida temporal, dá lugar a disputas entre os diferentes protagonistas vítimas, agressores, testemunhas e operadores técnicos (todos aqueles atores que dispõem de saber especializado, adquirido em formação profissional própria, exercitada em ensino universitário) e não-técnicos ${ }^{2}$ do direito nesta arena particular que são os tribunais penais, em torno da verdadejurídica (cf. Foucault, 1994, v. II, pp. 538-646), que pode ou não convergir para a identificação de cul pados, penal mente responsáveis. I gualmente, trata-se de disputas em torno do modo por meio do qual os operadores técnicos do direito penal entendem como a justiça deve operar, como deve me diar conflitos e como deve garantir, ao final das contendas, que a ordem prevaleça sobre o caos, o bem sobre o mal.

Para tratar do tema da morosidade, este estudo baseia-se nos resultados de projeto temático de pesquisa realizado pelo $\mathrm{N}$ úcleo de Estudos da Violência (N EV/U SP), no período de 1995-1999³. A exposição está dividida 
em quatro itens. 0 primeiro é dedicado ao contexto histórico e teórico no qual situamos a emergência da justiça no Estado moderno. Tece ainda alguns comentários a respeito das mudanças que o aparel ho penal moderno, inclusive seus tribunais de justiça, vem enfrentando à custa da emergência denovas modal idades de criminalidadee da explosão de graves violações de direitos humanos ${ }^{4}$. 0 segundo é reservado a uma descrição sumária da pesquisa realizada, com especial destaque para os casos de linchamento selecionados e para o tratamento metodológico conferido à intervenção da justiça penal. 0 terceiro concentra-sena abordagem da morosidade processual, que aponta para os usos sociais do tempo judicial. Breve conclusão retoma os argumentos principais.

\section{A justiça moderna em seu tempo}

U m dos problemas mais recorrentes das ciências sociais, em particular da sociologia, é o da legitimidade da ordem social. Por que a ordem é melhor do que o caos, a paz é preferível à guerra, a obediência à revolta, a razão à paixão? D iferentes tradições sociológicas ofereceram respostas distintas para esse elenco de indagações, abordando-as sob recortes temáticos os mais variados. U m deles, particularmente de interesse para os propósitos desteartigo, éo tema da confiança nas instituições da moderna sociedadedemocrática. N osso foco não é a confiança social em geral (um tema sociológico por excelência), mas a confiança depositada pelos cidadãos em um tipo específico de instituição: aquelas encarregadas de aplicar leis penais, distribuir sanções e assegurar, pelo controle repressivo dos comportamentos desviantes danorma imperativa (a obediênciaàsleis), a coesão interna da ordem social.

Recenterevisão de literatura (cf. Silva, 2006) identifica três modelos teóricos de explicação. 0 primeiro reputa a traços ecaracterísticas da personalidade individual o apoio dos cidadãos às instituições democráticas. 0 segundo sustenta que diferentes tradições culturais revelariam maior ou menor inclinação para a obediência às leis e o respeito às instituições. 0 terceiro éo da performance institucional. $\mathrm{N}$ ão são os traços psicossociais ou as heranças culturais doscidadãos queos inclinam a apoiar o mundo regido por leiseinstituições; ao contrário, são as instituições e as leis que se tornam confiáveis junto aos cidadãos, à medida que os agentes institucionais decidem e agem segundo regras previamente instituídas, legitimamente reconhecidas como imperativas. Sob esta perspectiva, as instituições tendem a operar como parâmetros de previsibilidadeda ação governamental.
Schindler (1993), Flá viaSchilling (1994-95), H elena Singer, Iolanda M aria Alves Évora (1994-98), M aria Inês C. Ferreira (1995-98), M arinaAlbuquerque de M acedo Soares (199495), W ânia Pasinato Izumino, como coorde nadores decampo; Fernando Afonso Salla e LuísAntônio Francisco de Souza (Prefeitura M unicipal de São Paulo), como pesquisadores comissionados; Adriana $\mathrm{H}$ anff da Silva (199394), Adriana Loche, Amarilys Nóbrega de Almeida (1993-94), Cristina Eiko Sakai (1993-94), Cristina Neme(1993-94), Glauber Silva de Carvalho (1994-98), Helder R. Sant'Ana Ferreira, Jacqueline Sinhoretto (1993-98), M arcelo GomesJusto (1993-98), M ônica Varasquim Pe dro (1995-98), O laya Sylvia Portela H anashiro (1993-94), PetroneIla Maria Boonen (1995-98), como pesquisadores; Adriana Tintori (1997-98), Alessandra Olivato (199597), C arlos César Gra ma (1994-95), Célio LuisBatista Leite, Cláudia Garcia M agalhães (1997-98), Cristiane 
Lamin Souza Aguiar (1997), D aniela R. Flório (1996-97), D ébora P. M edeiros(1995-98), Dionedo Espírito Santo (1996-96), Fraya Frehse (1994), José H enrique Garcia (1995), M oisés Baptista (1997), Simone de Cássia Ribeiro (1995-97), Sueli SolangePereira(1997), Vilma A. da Silva (1995-97), Viviane 0 liveiraC ubas, como auxiliares de pesquisa.

\section{Aqui entendidos} como o conjunto de princípios, de caráter universal e universalizante, formalizado no contexto do Estado liberal-democrático tal como se desenvolveu no mundo europeu ocidental no curso do século XIX, que proclama os direitos à vida $\mathrm{e}$ às liberdades, civis e públicas, como direitos inalienáveisdo homem. Sua efetivação requer ação dos governos no sentido de protegêlos contra qualquer espécie de violação ou abuso (cf. Cassese, 1993, p. 8). No curso dos últimos duzentosanos, a comunidade internacional operou no sentido do alargamento desse conceito para incluir os direitos de terceira e
A formação da sociedadee do Estado modernos, largamente examinada pela sociologia histórica (cf. W eber, 1974; Tilly, 1996; Bendix, 1996), ensejou, primeiro, um sistema fiscal centralizado e estável; segundo, uma força militar profissional, permanente e sujeita a um comando central; terceiro, uma justiça cujas atribuições e prerrogativas constituem monopólio do poder público; quarto, uma administração burocrática fundada na existência de funcionários. A par desses processos, substantivas e radicais mudanças operaram nas formas de socialidade e sociabilidade, originalmente repertoriadas no clássico estudo de N orberto Elias (1990), estimulando uma nova economia moral capaz de retrair o espetáculo da violência gratuita e lúdica de uns em relação a outros e oferecer garantia de vida para um maior número ${ }^{5}$, garantia convertida em direitos - direito à vida e à liberdade, ao bem-estar, à segurança e ao acesso à justiça. Sob essa perspectiva, a justiça converteu-se em mediação dos conflitos nas relações políticas, sociais e interpessoais, evitando que o poder dos mais fortes eliminasse pura e simplesmente os mais fracos.

Esse longo processo demandou requisitosinstitucionais, entre os quais o maisimportante- o monopólio estatal da violência. É célebreafórmula we beriana: no interior de um território delimitado, o Estado moderno éjustamentea comunidade política que expropria dos particulares o direito de recorrer à violência como forma de resolução de seus conflitos (pouco importando aqui a natureza ou o objeto que os constitui). N a sociedademoderna, não há, por conseguinte, qualquer outro grupo particular ou comunidade humana com "direito" ao recurso à violência como forma de resolução de conflitos nas relações interpessoais ou intersubjetivas, ou ainda nas relações entre os cidadãos e o Estado. A queles que estão autorizados ao uso da violência o fazem em circunstâncias determinadas, em obediência ao império da lei, isto é, aos constrangimentosimpostospelo ordenamento jurídico. Legitimidadeidentifica-se, por conseguinte, com legal idade, elegalidade constitui, por conseguinte, o fundamento de um sistema jurídico confiável, isto é, um sistema cuja funcional idade e operações garantem previsibilidade de ações e resolução de conflitos segundo regras reconhecidas como legítimas. N ão sem razão, nesse arcabouço jurídico-político assegurar a paz constitui talvez a mais elevada tarefa do governante político.

$\mathrm{N}$ isso reside justamente o nascimento e a funcionalidade da polícia, dos tribunais de justiça penal e prisões modernos, inscritos nas reformas penais quetiveram lugar em praticamentetodas as sociedades do mundo ocidental capitalista a partir da primeira metade do século XIX. Inspiradas no ilumi- 
nismo punitivo (cf. Foucault, 1975), previram isonomia de tratamento le gal. Todos devem ser submetidos de forma igual às leis constitucionais e penais independentemente de sua condição de classe, sexo, geração, raça ou qual quer outra clivagem socioeconômica e cultural ${ }^{6}$. Todo e qual quer cidadão acusado dehaver cometido crimestem direito a defender-se eser defendido, a ter acesso a todas as informações processuais e somente ser considerado condenado após o trânsito em julgado de sentença judicial. Previram igualmente a constituição de forças policiais com a função de prevenir e reprimir crimes, bem como investigar a autoria das ofensas às leis penais (cf. M onet, 2001; Bayley, 2001). N a mesma direção, a configuração de um sistema de justiça criminal fundado na racional ização do direito penal, naformação especializada, na profissional ização das funções da justiça, e assente em três princípios básicos: positividade, legalidade eformalidade ${ }^{7}$, capaz de individualizar a responsabilidade nos crimes e distribuir sanções. N esse domínio, o respeito às formalidades processuais é garantia de justiça. Impede tanto os abusos de toda sorte, inclusive o apelo a recursos extral egais como forma de influenciar decisões judiciais, como o cerceamento do direito de defesa, fonte de injustiça.

Esse modelo persistiria como uma narrativa ou apologia da justiça moderna não fossem as abruptas mudanças que vêm instituindo quebras de confiança entre os cidadãos e seus governantes. D esde os anos de 1960, no mundo ocidental, sondagens de opinião e estudos especializados vêm anotando, com insistência, o declínio da confiança depositada nos governantes, nos governos, nos mecanismos de partici pação e representação (parlamentos e congressos, partidos políticos, sindicatos, associações de classe), nas instituições públicas em geral (cf. Levi, 1998). Trata-se de um fenômeno percebido na América do $\mathrm{N}$ orte, na Europa 0 cidental e mesmo nas recémdemocracias, egressas de regimes comunistas, do Leste Europeu. Na Amé rica Latina, o forte desejo de redemocratização que tomou conta da região nas décadas de 1980 e 1990 mostra sinais de esgotamento e de desconfiança nos governos democráticos (cf. PN U D , 2005; Latinobarómetro, 2007).

A desconfiança parece mais acentuada quando estão em foco as instituições encarregadas do controle de lei e ordem, como polícias emesmo tribunais de justiça criminal. Parece haver correspondência entre o declínio de confiança ea intensificação dos conflitos sociais cuja resolução não conhece amediação dasinstituições públicas democráticas, inclusivegraves violações de direitos humanos ea escalada do crime urbano, em todas as suas modalidades, à custa da expansão da criminal idadeorganizada em dimensõesinter- quarta gerações, inclusive proteção dos direitos para grupos com identidade própria, como mulheres, crianças, refugiados. Para a história dos direitos humanos, ver também Bobbio (1992), Comparato (2007) e Ishay (2007).

5. Todo esse processo é bem mais complexo do queépossível expor nos limites deste artigo. 0 que importa destacar é a convergência entre a nova economia moral, fundada em relações hierárquicas menos assimétricas, e a centralização do poder político em torno do Estado burocrático-legal, quejustamentepermite situar a problemática da confiança nas instituições de justiça, em especial asincumbidas de aplicar lei e ordem. É o que se pretende sustentar ao longo da exposição que se segue.

6. Ver a propósito oses tudos sobre sentencing queexploram ainfluência defatores extral egais nos julgamentos. Ver $L$ andreville e Pires (1985) eDixon (1995).

7. Positividade porque o direito moderno exprimea vontade deum 
legislador soberano, 0 qual, por intermédio de meios jurídicos de organização, regulamenta as atividades da vida social. Legalidade porque "não reconhece outro ordenamento jurídico que não seja estatal, e outra forma de ordenamento estatal quenão sejaa lei" (Bobbio, 1984). Formalidade porque 0 direito moderno define o domínio no qual se pode exercer legitimamenteo livre-arbítrio das pessoas privadas (cf. Habermas, 1987, vol. 1). nacionais. No debate público, tem sido comum o argumento segundo 0 qual quanto mai or a impunidade, menor a confiança nas instituições encarregadas de aplicar as leis. Elevadas taxas de impunidade significariam que essas instituições não estariam cumprindo as tarefas para as quais foram originalmente criadas eformalizadas em suas constituições. Por certo, as novas modalidades deviolência ecrime, a par deoutros efeitossobreas instituições de controle social, têm perturbado o andamento convencional dos processos, contribuindo possivelmente para o alargamento da morosidade.

Intervenção judicial e direitos humanos

Como já suficientemente demonstrado pela literatura especializada (cf. C ardia, 1999), a transição da ditadura (1964-1985) para a democracia inaugurou uma era de profundas mudanças em torno de três eixos principais: abertura da economia brasileira ao mercado internacional, reconstrução da normalidade institucional com o retorno ao estado de direito - e tudo o que isso representava em termos de liberdades públicas, isto é, eleições livres, imprensa livre, sindicatos livres, pluralismo partidário - e intensa mobilização social de que resultou nova equação política das relações entre sociedade civil organizada e sociedade política. N esse contexto de mudanças, expressivos segmentos da sociedade civil organizada revelavam expectativas de que a violência seria erradicada, pois afinal o entulho autoritário seria banido do quadro político-institucional democrático, em particular as práticas arbitrárias de repressão à dissidência política. N ão mais haveria torturas, perseguições, banimentos, clandestinidade. Esperava-se que a reconstrução democrática promovesse a conciliação nacional e, em decorrência, a pacificação interna da sociedade. $\mathrm{N}$ ão foi o que se verificou.

Paradoxalmente, à medida que a sociedade se mobilizava para a reconstrução das instituições democráticas que viriam a ser inscritas na Constituição (1988), os conflitos sociais tornaram-se mais acentuados. N esse contexto, a sociedade brasileira vem conhecendo crescimento das taxas de violência, nas suas mais distintas modalidades: crime comum, violência fatal conectada com o crime organizado, graves violações de direitos humanos, explosão de conflitos nas relações interpessoais e intersubjetivas. Em especial, a emergência do narcotráfico promovendo a desorganização das formas tradicionais de vida entre as classes populares urbanas, estimulando o medo das classes médias e altas e enfraquecendo a capacidade do poder público de aplicar lei e ordem tem grande parte de sua responsabilida- 
de na construção desse cenário de insegurança coletiva. Em outras palavras, a sociedade mudou, os crimes cresceram e tornaram-se mais violentos, mas as instituições encarregadas da proteção dos cidadãos, bem como de aplicar lei e ordem, permaneceram operando segundo o mesmo modelo utilizado há três ou quatro décadas.

Estudos de sociologia histórica, já mencionados, sugerem que a marcha do processo civilizatório moderno e a consolidação da democracia nas sociedades ocidentais do hemisfério norte resultaram no controle social e estatal da violência. N essa direção, estudiosos da polícia têm demonstrado ser possível conciliar as funções repressivas dessa agência de controle social com as demais instituições e valores das sociedades democráticas (cf. G oldstein, 2003). Por que sociedades como a brasileira, com suas características singulares de organização social, não logram promover a reforma de suas instituições de justiça criminal de forma a torná-las mais confiáveis aos cidadãos comuns? Por que razões a violência, em todas as suas modalidades, persiste como um dos principais desafios à consolidação da democracia nessa sociedade? Como o Estado encara seu papel de guardião da lei? Foram essas as questões que motivaram a real ização do já citado projeto integrado de pesquisa intitulado Continuidade autoritária e construção da democracia (cf. Pinheiro, Adorno, Cardia et al., 1999), no qual, entre outras questões, foi abordada a problemática da morosidade processual em casos de graves violações de direitos humanos.

A execução do projeto temático eintegrado de pesquisa consistiu na reconstrução de casos selecionados de violações de direitos humanos, que ocorreram em diferentes momentos da década de 1980 até o ano de 1989. Esse universo empírico compreende casos de violações do di reito à vida que têm como agente tanto autoridades investidas de poder público como cidadãos civis, violações perpetradas por meio de ações desencadeadas seja por indivíduos isolados, seja por coletivos, organizados ou não. Privilegiou-sea observação de quatro tipos de fenômenos: linchamentos, execuções sumárias cometidas por grupos de extermínio, violência policial eviolência rural.

A reconstrução de casos teve por fontes de informação primária esecundária relatórios oficiais, inquéritos policiais e processos penais, dossiês e boletins de $0 \mathrm{~N} \mathrm{Gs}$, relato de debates, notícias veiculadas em jornais e revistas (nacionaise estrangeiros). A par dessasfontes, recorreu-sea informações extraídas de entrevistas realizadas com diferentes atores: membros de comunidades onde ocorreram as violações, representantes das organizações policiais, do M inistério Público, do Poder Judiciário, das organizações não- 
8. Para uma descrição detalhada de todos os procedimentos de pesquisa e da perspectiva teórico-metodológica adotada no estudo ere construção de casos, remetemos ao capítulo 4 do relatório de pesquisa (cf. Pinheiro, Adorno, Cardia et al., 1999). governamentais, dos movimentos de defesa dos direitos humanos e de outros grupos que intervieram ou participaram do processo.

N o período selecionado para observação (1980-1989), foram identificadas aproximadamente 5 mil notícias de violação de direitos humanos em todo o país, nas modalidades consi deradas, veiculadas pela imprensa nacional periódica. Esse universo compreende, em verdade, 3.519 casos ocorridosno país em seu conjunto. D ado o volumeea impossibilidadedeanalisar detidamente todo esse universo, foi necessário realizar seleção segundo critérios determinados, quais sejam, presença da opinião pública por intermé dio da mídia; intervenção do poder público por meio das agências policiais, judiciais e judiciárias; e participação da sociedade civil, organizada e nãoorganizada, seja em virtude da identificação das comuni dades onde os casos ocorreram, seja em virtude da intervenção dosmovimentos sociais. 0 resultado desse trabalho possibilitou a identificação de 162 casos, ocorridos no eixo Rio-São Paulo. D estes, foi possível ter acesso aosinquéritos eprocessos penais, totalizando cerca de noventa volumes, de 28 casosocorridosno estado de São Paulo. 0 presente artigo está baseado no estudo dos dez casos de linchamento reconstruídos ${ }^{8}$.

A literatura que aborda a temática do linchamento é extensa. Contempla diferentes perspectivas teórico-metodológicas, reconhece diferentes modalidades de ação coletiva enfeixadas como linchamento, a par de controvérsias em torno da natureza dessas formas de associação e de seu conceito. Ainda que tais questões guardem relevância para o estudo realizado, não é o caso de deter-se no tratamento da literatura especializada, o qual se encontra bem documentado (cf. M artins, 1995, 1996; Sinhoretto, 2002; Singer, 2003). N esta pesquisa, linchamento compreendeu modalidades de ação coletiva, com o propósito de executar sumariamente um ou mais indivíduos aos quais é imputada a responsabilidade pelo cometimento de crimes e violências de toda sorte, inclusive ameaças, que perturbam a vida e a rotina de bairros populares ou espaços urbanos de extensa e intensa circulação de pessoas. Esse propósito é revelado por indícios observáveis, como gritos de intenção, posse de instrumentos letais (instrumentos contundentes, às vezes armas brancas e até mesmo armas de fogo), depredações de construções e edifícios, públicos e privados. Envolve tanto organização espontânea e efêmera como "vigilantismo" (moblynching). D istingue-se de execuções sumárias praticadas por grupos de extermínio ou esquadrões da morte, porque nestes é flagrante a existência prévia de grupo organizado com precípuo objetivo de eliminar suspeitos 
ou inimigos, não raro mediante contrato firmado com particulares, como comerciantes.

Embora parte da literatura considere essa modal idade de ação uma espé cie de crime social, optou-se por classificá-la como violação de direitos humanos. Sem pretender jogar maislenhana controvérsia presentena literatura especializada9 ${ }^{9}$, assim classificamos os linchamentos por entender que ocorrem por omissão do Estado nas suas tarefas de proteção dos direitos e garantias individuais, inclusive o direito à segurança. É justamente essa omissão que pode estimular a aplicação de justiça imediata (isto é, sem mediações das instituições legais para controle social), "Iíquida e certa" nostermos da linguagem jurídica corrente.

O s dez casos tiveram lugar no estado de São Paulo. À exceção de um, ocorrido na praça da Sé, centro do município de São Paulo, todos ocorreram em bairros populares da região metropolitana dessa cidade e em $C$ ampinas. Seus protagonistas - vítimas, agressores e testemunhas - compõem 0 que, grosso modo, se poderia nomear de classes populares urbanas, constituídas em sua grande maioria de trabal hadores urbanos pauperizados, portadores de baixa escolaridade formal, ocupados em atividades que demandam pouca habilitação ou quase nenhuma especialização técnica. Aos baixos salários vêm associar-se as precárias condições de moradia urbana, em queé flagrante a carência de infra-estrutura, especial mente serviços de segurança pública, representados por policiamento eficaz e políciajudiciária eficiente.

A análise dos casos de linchamento esteve sustentada pela idéi de litígio, compreendido como um tipo especial de conflito social. Como sesabe, toda e qualquer forma de agrupamento social - envolva vínculos comunitários ou societários - supõe a existência de distintas formas de conflituosidade social, seja em uma perspectivamacro ou microssocial, quecompreendedisputas em torno dosmaisvariados objetos, materiaisou simbólicos. Taisconflitos podem atravessar toda uma densa redederelações sociai sou estar concentrados em regiões sociais determinadas. Podem assumir a forma de conflitos declasse, étnicos, raciais, degênero egeração, ou conflitosnas relações intersubjetivas, impulsionados pelos mais diversos móveis, ou mesmo mesclarem-se entre si. Em geral, buscam superar-se, seja pela supressão dos adversários, seja por meio de modalidades de acordo, de negociação ou de acomodação. 0 litígio é uma dessas modalidades que demandam necessariamente 0 apelo a uma instância de mediação e de julgamento, qualquer queseja ela, cujo resultado supõe a real ização de um sentimento coletivo de aplicação e de distribuição de justiça. Para responder a essas indagações, a
9. Parte dessa literatura consideralinchamentos como modalidades rústicas deaplicação dajustiça, com base na vingança, sem apelo àsleis e às instituições públicas demediação deconflito. N essamedida, são opostas aos modelos modernos de organização dos tribunaisdejustiça e seus correspondentes sistemas de justiça criminal. Parte da literatura, contudo, critica duramente essa dualidade, procurando identificar nessas moda lidades de ação significados que se situam além do conflito entre vítimaseseusal gozes (cf. M artins, 1995, 1996; Almeida, 1991). 
análise que se seguiu teve por objeto a intervenção judicial/judiciária nos casos delinchamento.

0 tempo da justiça

A análise da morosidade teve por fonte principal de informação os inquéritos e os processos penais instaurados para apuração de responsabilidade nos casos de linchamento. Trata-se de fonte muito rica, pois condensa a intervenção de diferentes protagonistas, além de permitir a caracterização decenários e contextos sociais e institucionais, as modalidades deação coletiva, os meios empregados, a intervenção dos agentes da lei. Sua principal limitação: todas as narrativas estão descritas sob o crivo e a ótica dos operadores técnicos e não-técnicos do direito. $\mathrm{N}$ ão obstante, para mensurar 0 tempo da justiça, os autos constituem instrumento, senão ímpar, essencial.

Para o tratamento da morosidade foi necessário inicialmentereportar-se ao Código Penal e ao Código do Processo Penal. Esses documentos legislativos descrevem os procedimentos e as formalidades que devem ser seguidos na condução de um processo, tipificam os crimes, regulam todas as fases pelas quais deve passar a apuração das responsabilidades e como deve operar o julgamento do ponto de vista formal, assim como determinam prazos para o cumprimento das providências e dos atos do processo. Com base nesses instrumentos formais, desenhou-se o organograma do fluxo do sistema de justiça criminal, desde o registro da ocorrência policial até a sentença judicial. Como os casos de linchamento analisados resultaram em desfechos fatais, classificados como crimes dolosos, são de competência do tribunal do júri, seguindo ritos processuais distintos daqueles próprios das varas criminais.

Em seguida, foi necessário construir duas réguas para mensurar o tempo despendido com os feitos judiciais, uma para os réus presos e outra para os soltos. Em linhas gerais, o procedimento consistiu em identificar e registrar todos os prazos estabelecidos nos códigos, com destaque para: o tempo de duração dos inquéritos; o tempo para a anexação dos exames técnicos aos autos; a quantidade de pedidos de dilação de prazo durante o inquérito e 0 tempo de tramitação de cada pedido; períodos em que nenhuma providência foi realizada; intervalo entreo oferecimento da denúncia pelo promotor público eo interrogatório do réu; tempo gasto por promotores, juízes e advogados para suas manifestações; duração da instrução criminal; tempo gasto com as interrupções provocadas pelo aguardo do cumprimento das solici- 
tações (por exemplo, localização de testemunhas, de réus, certidões oficiais, levantamento de provas); tempo gasto com a substituição de defensores, principalmente nos casos de defensores dativos; tempo gasto com as providências ordinárias do rito processual - abertura do inquérito, conclusão do inquérito, denúncia, recebimento da denúncia, interrogatório dos réus, oitiva detestemunhas, defesa prévia, al egações finais, pronúncia, libelo econtralibelo acusatório, e julgamento pelo tribunal do júri; duração total do processo.

A seguir apresenta-sea seqüência dosatose dos prazos definidosno Código do Processo Penal - CPP para os casos decompetênciado tribunal do júri.

\section{QUADRO 1}

Andamento do Processo no Tribunal do Júri de A cordo com a Situação do Réu (prazos extraídos do CPP)

\begin{tabular}{l|c|c}
\hline RITOS PROCESSUAIS & RÉU SOLTO & RÉU PRESO \\
\hline Inquérito policial & 30 dias & 10 dias \\
$\quad$ Anexação de laudos & 10 dias & 10 dias \\
M anifestação do M inistério Público & 15 dias & 5 dias \\
$\quad$ O ferecimento da denúncia & 5 dias & 5 dias \\
Outras manifestações & 1 dia & 1 dia \\
Despacho do juiz & 2 dias & 2 dias \\
Cumprimento dos despachos pelo cartório & 3 dias & 3 dias \\
Apresentação de defesa prévia & 40 dias & 20 dias \\
Audiência para oitiva de testemunhas & 5 dias & 5 dias \\
Apresentação das alegações finais pelo M P & 5 dias & 5 dias \\
Apresentação das alegações finais pela defesa & 2 dias & 2 dias \\
Saneamento de nulidades & 10 dias & 10 dias \\
Sentença intermediária & 5 dias & 5 dias \\
Apresentação do libelo acusatório pelo M P & 3 dias & 3 dias \\
Apresentação do libelo acusatório ao réu & 5 dias & 5 dias \\
Apresentação do contralibelo pela defesa &
\end{tabular}

Fonte: Código do Processo Penal.

Antes de expor resultados, al guns comentários metodológicos. U ma das mais completas eatuais análises da morosidadeprocessual ${ }^{10}$ foi desenvolvida por equipe de pesqui sadores do $C$ entro de Estudos Sociais da U niversidade de Coimbra, liderada por Boaventura de Sousa Santos (cf. Sousa Santos et al., 1996). Essa investigação enfocou objeto duplo: de um lado, analisou o desempenho dos tribunais portugueses de primeira instância como institui-
10. A morosidade tratada nesteartigo éprocessual. Alcança todos os procedimentos administrativos desde 0 registro de Boletim de 0 corrência até a sentença decisória final. Compreende todas as peças que compõem 0 inquérito policial e o processo penal. Utilizaremos o termo morosidade processual com suas classificações como se verá a seguir. 
ções de resolução de litígios e de controle social; de outro, cuidou de observar o acesso dos cidadãos à justiça, abordando suas motivações para acionála, bem como suas representações quanto à eficácia dos direitos e do funcionamento das instâncias judiciais e judiciárias. N esse domínio, a questão da morosidade mereceu atenção especial na medida em que constitui uma das variáveis - um indicador mesmo - por meio da qual é possível avaliar o de sempenho dosoperadores do direito edas instâncias dedistribuiç̧ão dejustiça, certamente uma das interfaces entre o sistema jurídico e o sistema político em sociedades democráticas.

D einício, é preciso reconhecer flagrantes diferenças entre o projeto de investigação desenvolvido em Portugal e o projeto de investigação desenvolvido no N EV/U SP. A começar, os objetos são distintos, a despeito do campo comum deinvestigação constituído em torno do papel dajustiça na construção da democracia contemporânea em sociedades semi periféricas e periféricas, para reportar-seà conceituação do próprio Sousa Santos (1995). Q uanto àmetodologia, o projeto portuguêssustentou-sefundamentalmenteem procedimentosdecoletaeanálisededadosquantitativos, aindaquecasostenham sido selecionados para exame particularizado. No projeto N EV/U SP, desenvolvido em etapas, o essencial da investigação repousa no estudo de casos de violação de direitos humanos. Algo na mesma direção podeser dito quanto à observação eao exame analítico da questão da morosidade. N esse particular, porém, as diferenças são mais sutis e talvez não sejam tão relevantes, pois o Projeto N EV/U SP se apoiou decisivamente na experiência metodológica portuguesa. Essa a razão pela qual, inclusive, val eria a pena destacar os principaisaspectos desta experiência, antes de apontar as pequenas divergências.

Sousa Santos e colaboradores (cf. Sousa Santos et al., 1996) distinguem dois aspectos relacionados à morosidade processual: de um lado, espera-se que a justiça seja rápida porque a duração excessiva do processo judicial provoca a erosão da prova com graves conseqüências para a justa reparação do direito violado; de outro, a celeridade no andamento processual não pode ser de molde a comprometer a segurança jurídica e os direitos dos cidadãos. Por conseguinte, o tempo ideal de duração de um processo deve harmonizar rapidez e eficiência com a proteção dos direitos. A esse ponto médio denominam morosidade necessária, ou seja, o cumprimento dos prazos legais visto sob a ótica das práticas judiciais. É sob esseponto de vista que foi observada e analisada a morosidade processual. Empiricamente, o conceito foi operacionalizado levando-se em consideração prazos regulamentados em estatutos legais e tempos médios de andamento e/ou permanência 
deautos nas repartiçõesjudiciais, estimados com base em observação piloto in loco. Para efeitos de contagem do tempo, considerou-se o percurso desde o início do processo atéa resolução efetiva do litígio. N ão foram consideradas as fases préjudiciais (nas quais têm lugar mecanismos de negociação, mediação e conciliação anteriores à instauração da ação judicial propriamente dita), nem as fases pós-judiciais (nas quais ocorre o cumprimento da decisão proferida no processo, como pagamento de indenização, multa, recolhimento à prisão etc.). Esse procedimento permitiu, por conseguinte, alcançar o tempo médio de andamento de um processo judicial (civil e/ ou penal), bem como identificar casos de longa duração processual.

Feitas essas considerações, impõe-se apontar as diferenças entre a análise da morosidadeno estudo real izado pelos pesquisadores do Centro deEstudos Sociais da U niversidade de C oimbra e a análise empreen dida na pesquisa do N EV/USP. Em linhas gerais, os conceitos ea metodologia de contabilização do tempo são compatíveis. N o entanto, foi necessário introduzir adaptações em facedas peculiaridades do direito penal e processual penal brasileiros. Em primeiro lugar, nosso Código do Processo Penal não demarca prazos para determinadas operações ou atividades judiciais. Em não poucas circunstâncias, foi necessário estimar o transcurso "razoável" de tempo para esta ou aquela operação, esta ou aquela atividade. Para tanto, recorreu-se a consultas a diferentes cartórios com vistas a alcançar uma espécie de "tempo médio" queservissedeparâmetro edeestimativa. N o entanto, parasurpresadospesquisadores, a heterogeneidade derespostasàconsultaeratamanha que, namelhor das hipóteses, comprometia a fidedignidade que se esperava atribuir ao procedimento. M esmo assim, por meio demúltiplasesucessivas consultas, logrou-se alcançar algum consenso.

0 utra dificuldade enfrentada diz respeito à impossibilidadedetraduzir a morosidade necessária em termos de um diagrama padrão (régua) - como ocorreu no projeto português -, em virtude da natureza dos linchamentos. D e fato, conforme se procurará mostrar mais à frente, os casos enfocados não seajustam àduração média deum processo penal instaurado para julgamento de homicídio doloso, sujeito, portanto, ao tribunal do júri, média essa em torno de sessenta meses. Em geral, os casos de linchamento observadosultrapassam em muito essa expectativa. Assim, era preciso elaborar uma média especial que assegurasse a construção de um diagrama padrão para casos dessa espécie. Se assim não fosse, corria-se o risco de uniformizar situações certamente muito distintas, como são, por exemplo, aquelas relativas a um homicídio comum, ocorrido no âmbito das relações intersubjetivas, e 
aquelas pertinentes ao homicídio resultante de um linchamento, cujas motivações respondem a inquietações sociais de outra ordem e natureza.

M esmo considerando tais especificidades, observou-se ainda que os casos de linchamento não são homogêneos entre si no que concerneà duração do processo penal. U m procedimento mais adequado epreciso recomendaria a construção de múltiplas réguas, para além das duas aqui consideradas, que pudessem ser aplicadasa distintos casos delinchamento. D esse modo, a variável tempo estaria completamente "sob controle", permitindo alcançar resultados fidedignos e comparáveis entre si, e equiparáveis com outras espécies de violação de direitos humanos e com outros tipos de violência praticados contra a vida que teriam resultado em desfecho fatal. $N$ ão se logrou alcançar tamanha precisão metodológica.

A duração dos processos judiciais instaurados para apuração de responsabilidade penal nos casos de linchamento que resultaram em desfecho fatal encontra-se registrada no Gráfico 1.

GRÁFICO 1

Linchamentos em São Paulo, 1980-1989: D uração Total dos Processos (em meses)

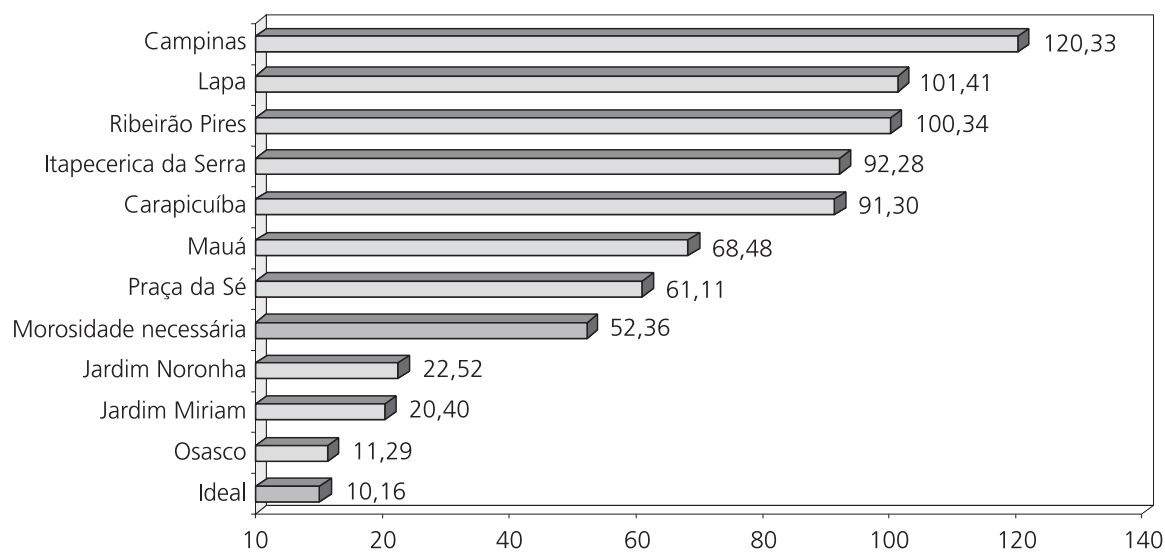

Fonte: Poder Judiciário. Inquéritos policiais e processos penais. Pesquisa N EV/U SP (1993-1999) [Fapesp/ CN Pq/FFord].

Conformesepodeverificar, a morosidadeideal (aquela resultantedacontabilização dos prazos previstos no Código do Processo Penal) prevê o dispêndio de 10,16 meses paraconclusão detodos os procedimentosjudiciaise judiciários, desde o registro da ocorrência policial até a sentença judicial transitada em julgado. C onvém observar queesselapso detempo inclui asfa- 
ses dedenúncia, pronúncia ejulgamento do homicídio doloso pelo tribunal do júri. A considerar esseparâmetro, todo o processo deveria estar concluído em menos de um ano. Trata-se evidentemente deum lapso de tempo pouco compatível com a realidade judicial/judiciária atual. C ertamente, quando 0 legislador o considerou, em fins da década de 1930, Ihe parecia uma medida razoável, ad equada a uma época em que a evolução da criminalidade ainda estava sob o controle das autoridades encarregadas da preservação da ordem pública. Com a aceleração do crescimento das taxas de violência criminal, desde a década de 1970, acentuada ao longo da década passada, o descompasso entre o volume de ocorrências e a capacidade de interven ção judicial/ judiciária ten deu a ampliar-se, implodindo os prazos regularmente estabele cidos. $\mathrm{N}$ a atualidade, os operadores técnicos do direito, quando entrevistados, ressaltam a caducidade desses prazos.

Por conseguinte, não é de estranhar que, à exceção do linchamento em O sasco, todos os demais casos se afastaram desse parâmetro temporal, a maioria dos quais de modo flagrantemente acentuado. 0 Gráfico 1 indica que, em apenas outros dois casos - os linchamentos ocorridos no Jardim M iriam e no Jardim N oronha -, a morosidade processual esteve abaixo da morosidade necessária. N os demais, esteve sempre acima desse parâmetro. $0 \mathrm{~s}$ inquéritos e os processos penais foram se arrastando por longos anos, muito além da morosidade necessária. As razões são variadas. G rosso modo, em al guns processos pesa mais o tempo despendido na obtenção de provas documentais (técnicas); em outros, o tempo é quase inteiramente consumido na localização e intimação de réus e testemunhas; em outros, firulas burocrático-legais, equívocos na condução dos procedimentos técnicos e legais, retenção dos inquéritos e/ou processos penais sem justificativa plausível respondem pela morosidade processual observada. Em alguns dos casos, cada um desses elementos tem sua parcela de responsabilidade; em outros, ela resulta de uma combinação desses elementos e circunstâncias determinadas. $\mathrm{N}$ ão parece, nesse domínio, ter-se identificado uma causalidade padrão. Ao menos parece razoável a hipótese levantada por Sousa Santos et al. (1996) a respeito do efeito cumulativo de uma causa sobre as outras.

Em virtude da caducidade desses prazos regulamentares, impôs-se, portanto, a necessi dade de recorrer ao exame da morosidadenecessária, de acordo com a conceituação anteriormente definida. N essa pesquisa, a morosidadenecessária foi estimada em 52,36 meses (quatro anos, um mêse seis dias). Ainda que esse lapso temporal possa estar ajustado às expectativas de cida- 
dãosbrasileirosquerecorrem (ou não) àjustiça pública na busca deresolução para seus litígios, expectativa aliás reforçada por padrões vigentes de cultura jurídico-política ecívica, eleéain da excessi vo quan do comparado com a morosidadelegal em outrospaíses, como seconstata pela leitura do Q uadro 2.

QUADRO 2

M orosidade Comparada (Processos Cíveis)

\begin{tabular}{l|l|l}
\hline País & TribunaL & M OROSIDADE \\
\hline FrançA & Tribunal de Grande Instance & 12,9 meses \\
(média 1976-1986) & Tribunal de Instance & 4,2 meses \\
\hline ITÁLIA & Tribunali Primo Grado & 26 meses \\
(1988) & Preture & 14,4 meses \\
\hline ALEM ANHA & Amstsgerichte & 4,5 meses \\
(1988) & Landgerischte & 8,9 meses \\
\hline PORTUGAL & Tribunais de Primeira Instância & 17 meses \\
(1988) & & \\
\hline
\end{tabular}

Fonte: "M orosidade processual nos Estados-membros da CEE (Programa Cidadão e Justiça)", 1991. Para Portugal: “Estatísticas de justiça”, 1988, em Sousa Santos et al. (1996).

Evidentemente, é preciso fazer al guns reparos. O s dados contidos neste Q uadro referem-se à litigação cível que, como se sabe, obedece a regras processuais distintas da litigação criminal. Assim, rigorosamente, esses dados não se prestariam a uma comparação com a morosidade processual observada nesta pesquisa. 0 s casos cíveis envolvem ações de diversa natureza, entre elas reconhecimento de paternidade; família ealimentos; divórcio e separação; herança e sucessões; reparações em acidentes de trânsito; responsabilização contratual; dívidas, prêmios, seguros; despejo urbano e rural; propriedade, posse expropriação; procedimentos cautelares, para mencionar algumas delas. D ependendo da natureza da ação, os processos podem arrastar-se anos nos tribunais, enquanto outros merecem rápida decisão judicial. Evidentemente, um raciocínio da mesma ordem poderia ser aplicado aos casos de competência da justiça penal. No entanto, é pouco provável que a morosidadenecessária nesses casos seja idêntica àquela observável para os casos de competência da justiça cível. $E$, mesmo que assim fosse, é de suspeitar que os agentes responsáveis pela morosidade revelassem a mesma composição, o mesmo peso ou a mesma combinação entre si.

I gualmente, a comparação não pode abstrair as profundas diferenças de tradição e organização judiciais nos países acima relacionados. Certamente, as interfaces entre o sistema judicial e o sistema político teriam que ser 
levadas em consideração, em particular as relações com os poderes Executivo e Legislativo, assim como o peso da burocracia estatal e os traços da cultura política que mediatizam as relações entre os cidadãos e o aparel ho judicial. Todos esses elementos, tomados isoladamente ou combinados entresi segundo determinada configuração, acabam influenciando a oferta de serviços judiciais, notadamente a capacidade de distintos sistemas judiciais responderem com rapidez e eficiência à resolução de litígios, seja nas relações entre classes e grupos sociais, seja nas relações intersubjetivas.

Ademais, as interfaces entre sistema judicial e sistema político teriam ainda que ser examinadas sob a ótica da natureza mesma do conflito intermediado, pois o peso e a influência de cada um dos elementos acima mencionados podem variar não apenas em função de distintas tradições e organizações judiciárias, mas também da natureza do litígio. Por exemplo, é possível que, nos conflitos cuja resolução seja do domínio da justiça cívil, os cidadãos revelem maior capacidade de pressão sobre as instâncias judiciais, traço reforçado por uma cultura política que val oriza a preservação de interesses relacionados à família, à propriedade, aos interesses ligados às atividades produtivas em geral etc. Em circunstâncias como esta, émuito possível queo perfil da burocracia estatal seja outro e que as relações entre o sistema judicial e o político ensejem decisões judiciais rápidas. N esse cenário, a morosidade processual poderá estar ajustada às expectativas dos cidadãos por soluções rápidas. Contudo, outro pode ser o cenário quando estão em foco os conflitos cuja resolução cai no âmbito da justiça criminal.

Finalmente, convém observar que, via de regra, os casos de competência da justiça cível dificilmente são carreados e julgados em tribunal do júri, circunstância que tende a tornar o percurso processual mais moroso. M esmo nos casos afetos à justiça criminal, não é comum sêlo. Em Portugal, por exemplo, o julgamento de litígios criminais pelo júri depende de recurso formulado e endereçado às autoridades judiciárias pela defensoria. Dependendo do desenrolar do caso, a estratégia da defensoria consistirá justamente em avocar o concurso do júri. M as, pelo que se sabe, não é rotina fazêlo, razão por que a maior parte dos casos é julgada pelos tribunais singulares. No Brasil, como afirmado anteriormente, os homicídios dolosos constituem competência exclusiva do tribunal do júri, instituto cuja sentença condenatória ou absolutória não pode ser reformada, no todo ou em parte, por nenhuma instância judiciária superior, exceto no tocante ao quantum eà natureza da pena, e exceto quanto à anulação do processo em virtude de vício ou erro reconhecido nos procedimentos judiciais e/ou em 
seu andamento. Em virtude dessas características, a distribuição da justiça penal faculta a intermediação de não poucos recursos judiciais atéa decisão final, transitada em julgado, o que constitui um componente a mais da morosidade processual, como aliás censuram não poucos operadores técnicos do direito, em especial os magistrados.

Caso fosse possível abstrair todas essas ponderações que turvam o rigor que se deveimprimir às análises comparativas, seríamos necessariamentelevadosà conclusão de quea morosidade processual nos casos delinchamento observadosnesta pesquisa está muito a lém da morosidadenos países relacionados. M esmo comparando com Portugal, país cuja morosidade é a mais acentuada em face dos demais, ainda assim nosso lapso detempo étrês vezes maior, ou seja, no intercurso de tempo necessário para o julgamento de um caso de homicídio doloso resultante de linchamento (ocorrido no município deSão Paulo ou em sua região metropolitana), são julgados três processoscíveis em Portugal.

TABELA 1

M orosidade em Crimes D olosos Contra a Vida no M unicípio de São Paulo Segundo D esfecho Processual*

\begin{tabular}{|c|c|c|c|c|c|c|c|c|}
\hline DURAÇÃo/D ESFECHO & ABSOLVIÇÃo & $\%$ & Condenação & $\%$ & DESCLASSIFICAÇÃO & $\%$ & TOTAL & $(\%)$ \\
\hline$<12$ MESES & 26 & 36,62 & 70 & 40,7 & 20 & 37,04 & 116 & $(39,05)$ \\
\hline 12-24 M ESES & 32 & 45,07 & 73 & 42,44 & 27 & 50 & 132 & $(44,44)$ \\
\hline 24-36 M ESES & 9 & 12,68 & 24 & 13,95 & 7 & 12,96 & 40 & $(13,46)$ \\
\hline 36-48 M ESES & 3 & 4,23 & 2 & 1,16 & - & - & 5 & $(1,68)$ \\
\hline SEM InformaÇão & 1 & 1,41 & 3 & 1,74 & - & - & 4 & $(1,34)$ \\
\hline TOTAL & 71 & 100 & 172 & 100 & 54 & 100 & 297 & (100) \\
\hline$\%$ & 23,91 & & 57,91 & & & & & \\
\hline
\end{tabular}

*M unicípio de São Paulo, IV Tribunal do Júri, Fórum Regional da Penha (1984-1988).

Fonte: Processos penais, Pesquisa N EV/U SP-CED EC, 1989.

M esmo para os padrões dominantes najustiça criminal no estado deSão Paulo, a morosidade processual, constatada nesta investigação, é excessiva. $D$ ados extraídos deoutras pesquisaso indicam. A pesquisa Violência urbana, justiça criminal eorganização social do crime (cf. Adorno, 1991, 1994) ocupou-se da observação de 297 processos penais instaurados para apurar a responsabilidade em crimes dolosos contra a vida, julgados em um dos tribu- 
naisdejúri dacapital deSão Paulo, no período dejaneiro de 1984 ajunho de 1988 (ver Tabela 1). Como se pode constatar, a grande maioria dos casos julgados $(83,49 \%)$ mereceu decisão judicial em até 24 meses após o registro da ocorrência policial, o que é um lapso temporal razoável se se considerar queos procedimentos judiciais nos casos de competência do tribunal dejúri são mais extensos - porém nem tanto, como revelam os dados - do que aqueles cuja atribuição está afeta às varas criminais.

Essa tendência independe do desfecho processual, pois as proporções em casos de absolvição $(81,69 \%)$, de condenação $(83,14 \%)$ e desclassificação $(87,04 \%)$ não apenas são uniformes entre si como também se encontram na mesma faixa de morosidade. I gualmente uniformes são as proporções de processos penais cuja morosidade oscilou entre 24 e 36 meses: $12,68 \%$ naqueles em que o desfecho resultou em absolvição; 13,95\% em condenação; e 12,96\% em desclassificação. É irrelevante a proporção de casos cuja morosidade tenha ultrapassado esse lapso temporal (1,68\%).

I zumino (1998) chegou a conclusões semelhantes. Seu estudo analisou a intervenção judicial em conflitos nas relações de gênero que resultaram em desfecho fatal para mulheres ou em lesões corporais. $N$ os casos em que se verificou desfecho fatal, 40,96\% dos processos instaurados foram encerrados entre doze e 24 meses. Em idêntica proporção (21,69\%), situam-se processos que tiveram desfecho em menos de doze meses ou entre 24 e 36 meses. É bem menor a proporção de processos encerrados em 48 meses $(8,43 \%)$, e menor ainda a proporção daqueles que consumiram tempo superior a 48 meses $(1,20 \%)^{11}$.

Assim, nos homicídios dolosos, cujo julgamento é atribuição exclusiva do tribunal de júri - o que, como já se disse, tende a ampliar o consumo de tempo necessário até a sentença decisória, quando menos porque seus procedimentos processuais reclamam dois despachosjudiciais (o de denúnciae o de pronúncia) - , a morosidade padrão não parece exceder 24 meses. Esse lapso de tempo também não destoa daqueles referidos à comparação internacional ( $Q$ uadro 2), mormente se considerado que o litígio civil não de manda o recurso ao tribunal dejúri. Portanto, uma vez mais, a distância que separa a morosidade processual nos homicídios comuns daquela pertinente aos homicídios resultantes de linchamentos permanece bastante acentuada.

Tudo indica que, nos casos que envolvem criminalidade comum ou conflitos nas relações intersubjetivas com desfecho fatal ou lesões à integridade física das vítimas, os operadores técnicos e não-técnicos do direito tendem a observar prazos legais ou, na ausência destes, os prazos fixados pela cultu-
11. Ver Pinheiro, Adorno e Cardia et al. (1999, cap. 19, p. 791). 
ra organizacional. 0 mesmo não ocorre com as graves violações de direitos humanos. Esses casos não parecem ajustar-se aos modelos normativos de julgamento propostos por nossas tradições de justiça penal.

Justiça e exclusão moral

Como se sabe, nossas tradições liberais de justiça penal assentam-se no princípio do livre-arbítrio, por meio do qual os indivíduos são considerados entidades morais capazes de discernir racionalmente entre o bem e o mal, entre o justo eo injusto, entre o certo eo errado, entre o legal eo ilegal. Sob essa perspectiva, os indivíduos são portadores de responsabilidade moral; neles repousam o desejo e/ ou a vontade de permanecerem obedientes à ordem social (isto é, obedientes às regras morais elegais dominantes), ou, contrariamente, ofenderem-namediantecomportamentosqueameacem aintegridade (física, psicológica ou moral) de quem quer que seja, e/ ou ainda ameacem o patrimônio público ou privado, a saúde pública, valores preservados como símbolos de uma identidade grupal ou nacional etc. Essa representação do homem como sujeito portador de razão e responsabilidade, capaz tanto de obedecer como de agredir, constituiu o solo no qual modernamenteseerigiu, em diferentes sociedades do mundo ocidental, uma sorte de justiça penal sustentada no tripé materialidade do delito-autorianexo entre materialidade e autoria. Todo seu modelo normativo e a cultura judicial que o pôs em funcionamento convergem, portanto, para a individual ização da responsabilidade penal sob o argumento de que as motivações são necessariamente restritas à órbita do indivíduo em seu mundo privado.

O ra, trata-se de um modelo normativo e de uma cultura judicial muito pouco compatíveis com a natureza de casos de violação de direitoshumanos. $\mathrm{N}$ a análise pormenorizada dos casos delinchamento selecionados, as motivações, a interven ção dos agentes sociais (agências e atores), a dinâmica dos acontecimentos guardam profundas diferenças diantedo quanto edo quese sabea respeito das motivaçõesqueimpulsionam o crime comum eseus autores. Dificilmente as motivações são individuais; a decisão ou não de linchar resulta de todo um processo social para o qual concorrem o compartilhar de experiências subjetivas comuns, a intensidade com que determinados fatose acontecimentos perturbam a vida eos sentimentos coletivos, a maior ou me nor presença da polícia e da justiça como instituições de intermediação de conflitos locais, bem como de outras agências de proteção e de intermediação, como igrejas egrupos deculto religioso, associações debairro, movimen- 
tos sociais, partidos políticos. Trata-se, por conseguinte, de um microcosmo social muito distinto daquelequeenvolveo mundo da criminalidadeurbana comum, ainda que el es mantenham entresi pontos de contato. D efato, embora não tenha sido possível nos limites deste artigo aprofundar a natureza dessas ações singulares que são os linchamentos, conseguiu-se constatar que o crescimento acelerado da criminalidade urbana violenta e as dificuldades das institui ções públicas de controlesocial em garantir segurança públicaparecem estar na raiz da ação dos litigantes, sejam vítimas, agressores ou testemunhas dos acontecimentos.

Convém sublinhar que os casos observados de linchamento ocorreram com freqüência em espaço público e em frente a prédios onde se encontram instaladas instituições que simbolizam poder, como escolas, postos de saúde, delegacias de polícia e igrejas. D o mesmo modo, em um dos casos observados, seus autores, constituídos como vigilantes do bairro popular onde moravam, haviam demandado maior segurança às autoridades locais, realizando um périplo que teve início junto ao prefeito, depois junto a vereador e deputado com bases el eitorais na região, eterminou no governador. 0 linchamento do suspeito ocorreu justamente após o esgotamento dessas instâncias de mediação. Em decorrência, tudo indica que, se tais conflitos não se resumem a um embate entre modelos distintos e opostos de justiça, seu móvel desencadeador passa necessariamente pela crença e confiança dos cidadãos comuns nas instituições encarregadas de promover lei e ordem e aplicar sanções aos autores de crimes.

Sob essa perspectiva, a longa morosidade processual nos casos de linchamento observados parece ser sintoma ao menos de duas ordens de fenômenos: deum lado, as dificuldades das agências de contenção da ordem pública edepacificação social em ajustá-losaosmodelos normativos dejustiça penal disponíveis e ao alcance dos operadores técnicos e não-técnicos do direito; de outro, as dificuldades desses próprios operadores em compreendêlos como casos passíveis de punição por meio das instâncias públicas de justiça. É como se esses operadores considerassem tais casos excluídos do contrato social, afetos ao mundo da natureza eà barbárie.

$\mathrm{N}$ unca édemais lembrar que, no linchamento ocorrido em 0 sasco, 0 inquérito foi arquivado sem nenhuma evidência da intenção de investigar 0 caso com vistas a punir os linchadores. 0 desempenho da agência policial sugere desi stência de aplicação das leis penais. Sob essa perspectiva, se considerarmos o tempo regularmente determinado para conclusão do inquérito policial (trinta dias), a morosidade legal foi justamente de 10,29 meses. 
N uncaédemais lembrar que, nesse linchamento, o desestímulo para o prosseguimento das investigações e da conseqüente ação penal foi simbolicamente selado com o depoimento da própria mãe do linchado, que declarou sentir-se aliviada com a morte do filho. Proferida por pessoa julgada a mais interessada no esclarecimento dos fatos e na punição dos agressores, a declaração acabou sendo interpretada simbolicamente como uma espécie de um duplo despacho dearquivamento: deum lado, autorização por "quem de direito"; de outro, condenação do caso ao esquecimento coletivo.

0 caso do Jardim M iriam refere-se ao linchamento de um homem, portador de distúrbios mentais, que matou e esquartejou sua sobrinha. 0 do Jardim N oronhatem como vítimaum delinqüentelinchado durante assal to a um bar. Ambos tiveram seusinquéritos policiais arquivados. Ambos parecem sugerir que o perfil das vítimas serviu como poderoso desestímulo ao prosseguimento das investigações. No primeiro deles, a linha de conduta adotada pel os agentes da polícia civil investiu na apuração da sanidademental do linchado, seus antecedentes e os motivos que o levaram a praticar 0 homicídio. Tudo pareceu concorrer para que o linchamento fosse considerado, sob a ótica das autoridades encarregadas deapurar os fatos epromover a punição dos linchadores, uma sorte de seqüência natural dos acontecimentos. N o segundo caso, não setomaram providênciasno sentido deidentificar suspeitos ou mesmo localizar testemunhas. D o mesmo modo, pouco esforço se fez para identificar e localizar o outro delinqüente que acompanhava a vítima durante 0 assalto, e que conseguiu escapar ao linchamento. $M$ ais do que desistência de punição, essa linha de conduta parece sugerir uma sorte de convergência entre o comportamento coletivo de populares quelincham eo comportamento daqueles encarregados depacificar a sociedadee preservar a ordem pública: ambos parecem movidos pela mesma desconfiança nas instituições públicas de resolução delitígios criminais. H á, no entanto, uma diferença singular: enquanto cidadãos comuns tomam a justiça em suas próprias mãos, autoridades públicas parecem reconhecer nessa modalidade dejustiçamento popular uma espécie de antecipação da justiça pública e oficial.

Referências Bibliográficas

Adorno, S. (1991), "Violência urbana, justiça criminal e organização social do crime". Revista Crítica de Ciências Sociais, 33: 145-156. Coimbra, Centro de Estudos Sociais. 
. (1994), "C rime, justiça penal e igualdade jurídica: os crimes que se contam no tribunal do júri". Revista USP, 21: 133-151.

Alm eid A, A. W. de. (1991), Extermínio de crianças no campo: violências contra crianças e adolescentes em conflitos de terra no Brasil (1980-1990). Rio de Janeiro, Centro Brasileiro para a Infância e Adolescência - CBIA.

BAYLEY, D . (2001), Padrões de policiamento. São Paulo, Edusp (série Polícia e Sociedade, 1).

Bendix, R. (1996), Estado nacional e cidadania. São Paulo, Edusp.

Bo ввı, N . (1984), D irei to eEstado no pensamento de Emanuel Kant. Braślia, Editora da UnB.

- (1992), A era dos direitos. Rio de Janeiro, Campus.

CARDIA, N . (1999), "Transições políticas: continuidades e rupturas, autoritarismo e democracia: os desafios para a consolidação democrática". In: PIn HeIRo, P. S., Adorno, S., Cardia, N . et al. (1999). Continuidade autoritária e construção da democracia. Projeto integrado (Fapesp/CN Pq/FFord). Relatório final, 4 vols. [site www.nevusp.org].

CASSESE, A. (1993), D erechos humanos en el mundo contemporáneo. Barcelona, Ariel.

Com parato, F. K. (2007), Afirmação histórica dos di rei tos humanos. São Paulo, Saraiva.

Correa, M . (1983), M orte em família. Rio de Janeiro, Graal.

D Ahrendorf, R. (1987), A lej e a ordem. Brasília, Instituto Tancredo N eves.

DIxON, JO. (1995), "The organizational context of criminal sentencing". American Journal of Sociology, 100 (5): 1157-98.

Elıas, N. (1990), 0 processo civilizador. Rio de Janeiro, Zahar, 2 vols.

Foucault, M. (1975), Vigiar e punir. Petrópolis, Vozes. . (1994), D its et écrits. Paris, Gallimard, 4 vols.

Gold stein, H . (2003), Policiando uma soci edadelivre. São Paulo, Edusp (série Polícia e Sociedade, 9).

H aberm AS, J. (1987), Théorie de l'agir communicationnel. Paris, Fayard, 2 vols.

I sH AY, M. R. (org.). (2007), D ireitos humanos: uma antologia. São Paulo, Edusp.

IzUmino, W. P. (1998), Justiça e violência contra a mulher: o papel do judiciário na solução dos conflitos de gênero. São Paulo, Annablume/Fapesp.

Lan d Reville, P. \& Pires, A. (1985). "Les recherches sur les sentences et le culte de la Ioi". L'Année Sociologique, 35: 83-113.

Latin obaróm etro. (2007), Informe Latinobarómetro 2007, banco de datos en línea.

Consultado no site www.latinobometro.org.

Levi, M . (1998), Trust and governance. N ova York, Russell Sage Foundation.

M ARTINS, J. de S. (1995). "As condições do estudo sociológico dos linchamentos no Brasil". Estudos Avançados, 9 (25): 295-310. 
. (1996), "Linchamento, o lado sombrio da mente conservadora". Tempo Social, 8 (2): 11-26.

M on et, C. (2001), Polícias e sociedades na Europa. São Paulo, Edusp (série Política e Sociedade, 3).

Pinheiro, P. S., Adorno, S.; Cardia, N. et al. (1999), Continuidade autoritária e construção da democracia. Projeto integrado (Fapesp/C N Pq/FFord). Relatório final, 4 vols. [site www.nevusp.org].

PN U D . (2005), A democracia na América Latina. Santana do Parnaíba, Programa das N ações U nidas para o D esenvolvimento - PNUD.

Sııva, N . C . (2006), "D esconfiança política nas instituições democráticas: quais suas causas e implicações para o funcionamento do regime democrático nas democracias consolidadas enas 'novas democracias'". Trabal ho apresentado no IV Simpósio dos Pós-G raduandos em Ciência Política da U SP. São Paulo, abr.

Sin Ger, H . (2003), D iscursos desconcertados: linchamentos, punições e di reitos. São Paulo, Humanitas/Fapesp.

Sin horetto, J. (2002), O s justiçadores e sua justiça. São Paulo, IBC rim.

Sousa Santos, B. (1995), Pela mão de Alice. São Paulo, Cortez.

Sousa Santos, B., Leitão Marques, M. M. \& Pedroso, J. (1996), Os tribunaisna soci edade contemporânea. Porto, Afrontamento.

TILly, Ch. (1996), Coerção, capitais e estados europeus. São Paulo, Edusp.

Weber, M . (1974), Economia y sociedad. M éxico, Fondo de Cultura Económica, 2 vols.

\section{Resumo}

A justiça no tempo, o tempo da justiça

Este artigo trata da morosidade da justiça penal. 0 tempo é medida da justiça. Se muito longo, é cada vez menos provável corrigir fal has técnicas na condução administrativa dos procedimentos ou localizar testemunhas, eventuais vítimas, possíveis agressores. Se muito curto, corre-se o risco de suprimir direitos consagrados na C onstituição e nas leis processuais penais, instituindo, em lugar da justiça, a injustiça. Para o cidadão comum, o tempo é lugar da memória coletiva. Se ele consegue estabelecer vínculos entre o crime cometido e a aplicação de sanção penal, experimenta a sensação de que a justiça foi aplicada e confere credibilidade às instituições encarregadas de distribuir justiça retributiva. Este artigo explora essas assertivas como base de estudo empírico sobre processos penais instaurados para apurar responsabilidade penal em linchamentos ocorridos no estado de São Paulo de 1980 a 1989.

Palavras-chave: D ireitos humanos; Violência; Linchamentos; Justiça criminal. 


\section{Abstract}

Justice in time and the time of justice

This article examines delays in the penal justice system. T ime is the measure of justice.

The longer a case takes, the less chance there is to correct technical failures in the administrative procedures or locate witnesses, other victims or possible aggressors. If too short, there is a risk of contravening rights enshrined in the Brazilian Constitution and penal laws, thereby producing injustice rather than justice. For common citizens, time is the place of collective memory. When they can make links between the crime committed and the application of penal sanctions, they feel that justice has been applied, conferring credibility to the institutions responsible for retributive justice. This article explores these claims through an empirical study of the penal investigations conducted to establish criminal responsibility for lynchings perpetrated in the state of São Paulo from 1980 to 1989.

Texto recebido e aproKeywords: H uman Rights; Violence; Lynchings; C riminal Law. vado em 22/11/2007.

Sérgio Adorno é professor titular do D epartamento de Sociologia daFFLCH -USP, coordenador do $\mathrm{N}$ úcleo de Estudos da Violência (N EV-C epid/U SP), coordenador da C átedra Unesco de Direitos H umanos, Educação para a Paz, Tolerância e D emocracia, sediada no Instituto de Estudos Avançados (IEA-U SP) e pesquisador I-B do CN Pq. Email: sadorno@usp.br.

W ânia Pasinato é doutora em Sociologia (USP), pesquisadora sênior do N EV-C epid/ U SP e pós-doutoranda junto ao $\mathrm{N}$ úcleo de Estudos de Gênero Pagu, da Unicamp, com apoio da Fapesp. E-mail: waniapasinato @uol.com.br. 